Int. J. Odontostomat., 4(1):33-41, 2010.

\title{
Agreement Evaluation of a Newly Proposed System for Malocclusion Classification
}

\author{
Acuerdo de Evaluación de un Sistema de Nuevas Propuestas \\ de Clasificación de la Maloclusión
}

Antonio Borges Miguel-Neto*; Clarice Nishio* \& José Nelson Mucha**

MIGUEL-NETO, A. B.; NISHIO, C. \& MUCHA, J. N. Agreement evaluation of a newly proposed system for malocclusion classification. Int. J. Odontostomat., 4(1):33-41, 2010.

\begin{abstract}
The current malocclusion classification systems, routinely used in orthodontic practice, still yield different disagreement values among examiners who evaluate one and the same clinical case. Objectives: The purpose of this study was to evaluate the agreement effectiveness of a Newly Proposed System for malocclusion classification - in the anteroposterior orientation -, conceived by the present authors. Thirty-four examiners evaluated 15 malocclusion cases using Angle's, Katz's and the Newly Proposed System classifications to determine which system shows the highest degree of agreement and accuracy when results were communicated among examiners. A comparison of the classifications attributed to each individual case and the mean figures found for the total data in each classification showed that the methods advanced by the Newly Proposed System yielded a higher degree of agreement (73.33\%) than Angle's (26.66\%) and Katz's (26.66\%). The Newly Proposed System proved to be an outstanding malocclusion classification system with a high degree of agreement among examiners. On the other hand, however, further studies involving a wider sample of malocclusions and a greater number of examiners are strongly recommended if more conclusive results are to be achieved.
\end{abstract}

KEY WORDS: Malocclusion classification systems, Angle's classification, Katz's classification.

\section{INTRODUCTION}

Classifying means distributing a topic into different classes or groups according to a given classification method or system (Ferreira, 1986). The act of classifying can render a given subject or pursuit more objective, understandable and consistent even if studied or analyzed by different people (Moyers, 1991).

In Dentistry, and particularly within the realm of Orthodontics, the concept of malocclusion classification dates back over two-hundred years as can be seen in the dental malformation classifications carried out by authors such as Meckel (1722), Fox (1803), Marjolin (1823), Schange (1841) and Carabelli (1842) reported in the study of Ackerman \& Proffit (1969).

It was in 1889, however, that Edward Hartley Angle developed an anteroposterior malocclusion classification system which, thanks to its straightforwardness and ease of use, is still extensively utilized in orthodontic practice to this day. Nevertheless, criticisms of Angle's classification system frequently appear in orthodontic literature, with numerous researchers claiming that it produces a low degree of agreement among examiners of one and the same case while lacking sufficient accuracy (Dewey, 1915; Gravely \& Johnson, 1973; Miguel-Neto \& Mucha, 2000; Rinchuse \& Rinchuse, 1989).

In view of this fact, a Newly Proposed System for malocclusion classification (Miguel-Neto \& Mucha) was developed with the purpose of ensuring a more precise classification of a greater number of cases while reducing divergence among orthodontists. This present study aimed to evaluate the agreement effectiveness of this new dental classification proposal by comparing it with two other anteroposterior malocclusion classification systems - Angle (Angle) and Katz (Katz, 1992b).

\footnotetext{
* Former Resident, Department of Orthodontics, Faculty of Dentistry, Fluminense Federal University, Niterói, RJ, Brazil.

" Professor and Department Chair, Department of Orthodontics, Faculty of Dentistry, Fluminense Federal University, Niterói, RJ, Brazil.
} 


\section{MATERIAL AND METHOD}

The materials used in this study comprised 102 malocclusion classification records. The anteroposterior malocclusion classifications were performed on fifteen pairs of plaster models, randomly selected from among patient cases kept in the archives of the Department of Orthodontics, at the School of Dentistry of the Fluminense Federal University, located in the city of Niterói, Rio de Janeiro State.

The criteria used in sample selection encompassed, (a) the presence of all permanent teeth, except for third molars; (b) teeth with normal anatomical shapes; and (c) teeth reflecting the many variation possibilities implied in anteroposterior relations. Thirtyfour examiners, all of whom students enrolled at PostGraduate Orthodontics Courses of four different Rio de Janeiro State Universities, classified the fifteen cases based on three malocclusion classification systems, namely (1) Angle's (Angle), (2) Katz's (Katz, 1992b), and (3) the Authors' Newly Proposed Classification System (Miguel-Neto \& Mucha).

The method consisted in comparing the agreement potential of the three different malocclusion classifications as well as comparing the percentage figures assigned to each classification. Classifications were recorded at regular weekly intervals so as to prevent trends that might be created through the influence of any particular classification system. The examiners firstly utilized Angle's, then Katz's, and then finally the Authors' Newly Proposed Classification System.

Prior to all classifications, instructions were provided by means of an explanatory text in addition to verbal explanations with the aid of slides to standardize classification methods. All classifications were performed in strict compliance with the reference points advocated by the author of each system as described in the literature reviewed (Angle; Katz, 1992b; Miguel-Neto \& Mucha). The examiners used a standard millimeter ruler to measure deviations from a normal relationship according to Katz's and the present study's classification systems.

As regards Angle's system, particular emphasis was placed on classifying the first permanent molars by observing the occlusion between the upper first molar's mesiobuccal cusp tip and the lower molar's mesiobuccal groove (Fig. 1).
The dental reference used for the Katz system was the anterior-most bicuspid and its interdigitation relative to the occlusal embrasure between the anterior-most lower bicuspid and its distally adjacent bicuspid. The tip of the cuspids on these teeth should be positioned at the embrasure formed by the distal contact of the anterior-most lower bicuspid, thus configuring a Class I. Classes II and III were determined when the cusp tips on these teeth were found to be displaced from the contact point, either towards mesial (negative) or distal (positive), respectively. All measurements were performed with the same millimeter ruler (Fig. 2).

The anatomical structure used as reference by the Newly Proposed Classification System was the tip of the distobuccal cusp on the first upper molar relative to the occlusal embrasure between the first and second lower molars (Fig. 3). When the tip of the distobuccal cusp pointed towards the occlusal embrasure between the first and second lower molar while any other tooth was found to be misaligned or maloccluded, a Class I was characterized. Any deviations of $1 \mathrm{~mm}$ and above from this relationship characterized a Class II, as long as the upper arch was positioned towards mesial and the lower arch towards distal (Fig. 4); and a Class III was defined whenever the upper arch was positioned towards distal - $1 \mathrm{~mm}$ and above -, or the lower arch towards mesial. Measurements were taken with the same millimeter ruler.

\section{RESULTS}

The data obtained by the 34 examiners who applied the three classification systems under study by Angle, Katz and the NewlyProposed System - to the fifteen pairs of models evaluated by the authors, are exhibited in Tables I to III. The results showed that the Newly Proposed Classification System classification attained the highest agreement values among examiners, presenting a consensus in eleven of the fifteen cases (73.77\%), followed by Angle's and Katz's systems, both with $26.66 \%$ of agreement, i.e., a concurrence in four of the fifteen cases.

As regards the time required by each examiner to classify the malocclusion cases, the results showed that Angle's system consumed the shortest evaluation 


time (10.44 minutes) while Katz's system and the Newly Proposed System required approximately the same amount of time for case assessment (17.50 minutes and 16.58 minutes, respectively).

Table I. Diagnosis agreement among the 34 examiners, in 15 cases of malocclusion, according to the Angle's classification.

\begin{tabular}{|c|c|c|c|c|c|c|c|c|c|c|c|c|c|c|c|}
\hline \multirow[b]{2}{*}{ Malocclusion } & \multicolumn{15}{|c|}{ Cases } \\
\hline & 1 & 2 & 3 & 4 & 5 & 6 & 7 & 8 & 9 & 10 & 11 & 12 & 13 & 14 & 15 \\
\hline $\mathrm{Cl} . \mathrm{I}$ & 9 & & 32 & & & 34 & 33 & 30 & 33 & 26 & 18 & 4 & 34 & 9 & 30 \\
\hline Cl. II & & & 1 & 34 & 34 & & & 2 & & & 14 & & & 5 & \\
\hline Cl. II (right) & 25 & & & & & & 1 & 2 & & & 2 & 15 & & 12 & 4 \\
\hline CI. II (left) & & & 1 & & & & & & 1 & & & & & & \\
\hline Cl. III & & 19 & & & & & & & & 6 & & & & 6 & \\
\hline Cl. III (right) & & & & & & & & & & 2 & & 15 & & & \\
\hline CI. III (left) & & 15 & & & & & & & & & & & & 2 & \\
\hline Others & & & & & & & & & & & & & & & \\
\hline
\end{tabular}

Table II. Diagnosis agreement among the 34 examiners, in 15 cases of malocclusion, according to the Katz's classification.

\begin{tabular}{|c|c|c|c|c|c|c|c|c|c|c|c|c|c|c|c|}
\hline \multirow[b]{2}{*}{ Malocclusion } & \multicolumn{15}{|c|}{ Cases } \\
\hline & 1 & 2 & 3 & 4 & 5 & 6 & 7 & 8 & 9 & 10 & 11 & 12 & 13 & 14 & 15 \\
\hline Cl. I & 2 & & & & & 25 & 2 & 2 & & 19 & & & 17 & 4 & 1 \\
\hline Cl. II & 28 & & 33 & 34 & 33 & 5 & 25 & 32 & 34 & & 34 & 6 & & 1 & 33 \\
\hline Cl. II (right) & 1 & & 1 & & & 1 & & & & & & 1 & 9 & 12 & \\
\hline CI. II (left) & & & & & & 3 & 6 & & & & & & & & \\
\hline Cl. III & 2 & 34 & & & 1 & & & & & 3 & & 14 & 2 & 5 & \\
\hline Cl. III (right) & & & & & & & & & & 9 & & 9 & & 1 & \\
\hline Cl. III (left) & & & & & & & & & & 3 & & 1 & & 7 & \\
\hline Cl. II and III & 1 & & & & & & & & & & & 3 & 6 & 3 & \\
\hline Others & & & & & & & 1 & & & & & & & 1 & \\
\hline
\end{tabular}

Table III. Diagnosis agreement among the 34 examiners, in 15 cases of malocclusion, according to the Newly Proposed System's classification.

\begin{tabular}{|c|c|c|c|c|c|c|c|c|c|c|c|c|c|c|c|}
\hline \multirow[b]{2}{*}{ Malocclusion } & \multicolumn{15}{|c|}{ Cases } \\
\hline & 1 & 2 & 3 & 4 & 5 & 6 & 7 & 8 & 9 & 10 & 11 & 12 & 13 & 14 & 15 \\
\hline Cl. I & & & & & & & & & 9 & 34 & & & 6 & & \\
\hline Cl. II & 34 & & 34 & 34 & 34 & 34 & 30 & 34 & 25 & & 34 & 2 & & & 34 \\
\hline Cl. II (right) & & & & & & & 4 & & & & & & 28 & 34 & \\
\hline \multicolumn{16}{|l|}{ CI. II (left) } \\
\hline CI. III & & 34 & & & & & & & & & & & & & \\
\hline Cl. III (right) & & & & & & & & & & & & 32 & & & \\
\hline \multicolumn{16}{|l|}{ Cl. III (left) } \\
\hline \multicolumn{16}{|l|}{ Cl. II and III } \\
\hline Others & & & & & & & & & & & & & & & \\
\hline
\end{tabular}




\section{DISCUSSION}

Malocclusion classifications are performed by taking into account biological variations in an attempt to facilitate communication and provide a basis for diagnosis. For the sake of clinical relevance, classifications should be simple, straightforward and pragmatic (William \& Stephens, 1992).

In 1889, Edward Hartley Angle made a landmark contribution to the history of malocclusion classifications by defining three malocclusion classes based both on the anteroposterior relationship between cuspids and on the occlusion of the mesiobuccal cusp of the first permanent upper molar with the mesiobuccal groove of the first permanent lower molar (Angle). Nevertheless, frequent criticisms can be found in the literature, which tend to consider such classification method as limited, ambiguous and even incapable of handling all malocclusion cases (Cryer, 1904; Van Loon, 1915; Hellman, 1920; Simon, 1932; Strang, 1938; Ackerman \& Proffit; Hellman, 1943; Hermanson \& Grewe, 1970; Andrews, 1972; Grewe \& Hagan, 1972; Gravely \& Johnson; Proffit \& Ackerman, 1973; Rinchuse \& Rinchuse; Katz et al., 1990; Katz, 1992a; Katz, 1992b; Williams \& Stephens; Du et al., 1998; Luke et al., 1998; Miguel-Neto \& Mucha).

According to certain concepts advanced by Stoller (1954) and Andrews, proper interdigitation in the normal occlusion of anterior teeth can only occur when the first upper molar is positioned towards mesial of the mesiobuccal groove of the first lower molar. The authors of this study therefore advocate a Newly Proposed System for classifying malocclusions in the anteroposterior orientation, based on the relationship between the distobuccal cusp of the first upper molar and the occlusal embrasure located between the first and second lower molars.

The upper first molar was selected as the reference tooth for the Newly Proposed Classification System since, according to Angle, this tooth provides a number of advantageous features. Upper first molars are wider than average, are firmly implanted, are positioned at a key arch location, allow the determination of vertical dental and skeletal proportions due to their considerable length; they develop into a normal position more often than other teeth owing to the fact that they are the first permanent teeth to erupt; their eruption chronology is more consistent than that of other permanent teeth; and, finally, the determination of the interarch relationship of all other teeth is based on their eruption and "interlocking" with the lower first molars.

In the present study, incisors were not utilized as reference by the Newly Proposed Classification System since some authors (Gravely \& Johnson; Williams \& Stephens; Du et al.) have demonstrated that incisor-based classifications have raised agreement issues among examiners, particularly with regard to Class II, second division. Cuspids were not used as reference by the Newly Proposed System either since these teeth feature a number of undesirable characteristics. Upper arch cuspids are the last teeth to erupt and as a result tend to emerge crookedly and often remain impacted. In addition, cuspids often develop anatomical alterations, such as a long axis that does not align with the cusp center, and a mesial edge which is smaller than its distal counterpart.

Such shortcoming may hinder a direct occlusion of the upper cuspid with the embrasure between the lower cuspid and the first bicuspid. Bicuspids, on the other hand, can also prove problematic when it comes to their dental positioning, namely, their absence and/ or agenesis, as well as their inadequate positioning may render the classification (Miguel-Neto \& Mucha) task rather difficult. Both cuspids and bicuspids were therefore ruled out as classification references.

The results achieved by the present study showed that the Newly Proposed Classification System (73.33\%), compared with Angle's and Katz's systems (26.66\% for both), yielded a higher degree of agreement among examiners - versus respectively. These results corroborate those found by Dewey; Gravely \& Johnson; Rinchuse \& Rinchuse; Katz (1992b); Williams \& Stephens; Du et al.; and Luke et al., who also found a low degree of agreement among examiners when using Angle's classification system.

The fact that Angle's system generates disagreement can be explained by a lack of precise, quantitative limits between malocclusion classes (Gravely \& Johnson; Miguel-Neto \& Mucha; Rinchuse \& Rinchuse). Moreover, as asserted by Du et al., Angle's classification system seems to be deficient insofar as class definitions and descriptions are concerned, thus allowing class overlap. In this study, this fact was well evidenced in the case of number 14 , 
where there was an overlapping of malocclusion classification. In contrast, the examiners showed a full agreement of diagnosis when the same case was analyzed by using the Newly Proposed System. However, the agreement values found using Angle's classification system were the same to those yielded by Katz's, which leads us to believe that neither system is superior to the other Du et al. in terms of agreement.

Another issue arising from Angle's classification system, and which contributed in great measure to the results, is the fact that it does not strictly circumscribe a reference point for Class I. Throughout this study it became evident that evaluators had to grapple with the classification of cases in which the mesiobuccal cusp of the upper first molar rested a few millimeters either mesially or distally of the mesiobuccal groove of the lower first molar. Had such cases been classified as Class I, the principle of classifying as Class I those cases in which the cusp of the first upper molar occludes precisely with the mesiobuccal groove of the first lower molar, could not possibly apply to all cases (MiguelNeto \& Mucha).

Although Katz's classification system showed a low degree of agreement amongst examiners, it should nevertheless be underscored that it features certain very clear advantages, i.e. (a) Class I is regarded as a treatment objective and not simply a space with a 7 $\mathrm{mm}$ variation, as proposed by Angle; (b) The degree of malocclusion is classified with accuracy, in millimeters, considering both sides discretely; and (c) Patients' halfarches can be classified separately, with Class II on one side and Class III on the other (Katz, 1992b).

All the three classification systems showed different deficiencies. Disagreement among examiners who utilized Katz's classification system were related to difficulties in evaluating partially erupted bicuspids and bicuspids with misalignment due to inclination and rotation for example (Miguel-Neto \& Mucha). Agreement among examiners who used Angle's classification system, on the other hand, was probably impaired on account of loosely defined criteria. The Newly Proposed System was not free from diagnostic discrepancies either, but although this is a new and original classification proposal, hitherto unknown and not yet mastered by the examiners, interpretation difficulties were reasonably anticipated and not allowed to interfere with its utilization.

The results showed that examiners spent the least amount of time classifying cases when using
Angle's system. This is probably due to the fact that molars are easier to use as reference. It can also be attributed to the examiners' prior training in this system. Katz's system and the Newly Proposed System systems required similar amounts of time for evaluation - 17.50 minutes and 16.58 minutes, respectively. Such longer classification times might be associated with the need to perform measurements with a millimeter ruler, which undoubtedly demands lengthier evaluation time.

It should be noted, however, that although examiners needed a shorter amount of time to evaluate cases using Angle's system, the Newly Proposed System yielded a greater degree of agreement in eleven out of fifteen cases after individual assessment of each case. It also achieved a much greater degree of agreement $(73.33 \%)$ than Angle's (26.66\%).

Study findings showing a moderate degree of agreement among examiners (Lischer, 1912; Simon; Hellman, 1943; Draker \& Albany, 1960; Björk et al., 1964; Summers, 1971; Gravely \& Johnson; Baume \& Maréchaux, 1974; Asbell, 1990; Hennet et al., 1992; Katz, 1992a; Du et al.; Brightman et al., 1999) demonstrate that methods featuring quantitative scales to measure malocclusion, combined with more strictly defined criteria and systematic training methods for practitioners, should be preferred in order to enhance communication and acquire data to support treatment recommendation and assess the actual severity of malocclusions.

In view of the results obtained from this investigation, the Newly Proposed Classification System, submitted by the present authors, has proved to be a reliable and practical tool for assessing and diagnosing malocclusion cases. This system facilitates treatment planning, if one takes into account that the ultimate treatment goal is to enable the distobuccal cusp to rest between the first and second lower molars. Furthermore, the Newly Proposed System allows a quantitative and accurate assessment of malocclusions on each side of the half-arch, in millimeters, thereby facilitating a more objective treatment plan. Finally, this system also allows the discrete classification of the patient's half-arches, e.g. Class II on one side and Class III on the other.

In conclusion, the results obtained from the present study lead us to conclude that:

The New Classification Proposal developed by the authors yielded a higher degree of agreement in 
eleven of the fifteen cases under classification, showing a mean agreement percentage of $73.33 \%$ versus $26.66 \%$ of Angle's and Katz's classification methods.

Angle's classification system, although simple, quick and practical, yielded low agreement values in those cases where the mesiobuccal cusp of the upper molar did not occlude exactly with the mesiobuccal groove of the lower molar.

The New Classification Proposal enabled greater accuracy in result communication; however, further studies, involving a greater number of cases and examiners, are needed to confirm these findings.

MIGUEL-NETO, A. B.; NISHIO, C. \& MUCHA, J. N. Acuerdo de evaluación de un sistema de nuevas propuestas de clasificación de la maloclusión. Int. J. Odontostomat., 4(1):33-41, 2010.

RESUMEN: Los sistemas actuales de clasificación de maloclusión, habitualmente utilizados en la práctica de ortodoncia, siendo los distintos valores un desacuerdo entre los examinadores que evalúan un caso clínico y o el mismo caso. El objetivo de este estudio fue evaluar la eficacia de una nuevo sistema propuesto para la clasificación de maloclusión - en la orientación anteroposterior -, concebida por los autores de este estudio. Treinta y cuatro examinadores evaluaron 15 casos de maloclusión utilizando las clasificaciones de Angle, Katz y el nuevo sistema propuesto de clasificación, para determinar cual de los sistemas muestran el mayor grado de acuerdo y precisión cuando los resultados fueron comunicados entre los examinadores. La comparación de las clasificaciones atribuidas a cada caso particular y las medias encontrada para los datos totales de cada clasificación mostró que los métodos avanzados del nuevo sistema propuesto dió un mayor grado de acuerdo (73,33\%) que (Angle 26,66\%) y Katz (26,66\%). El nuevo sistema propuesto demostró ser un sistema de clasificación de la maloclusión con un alto grado de acuerdo entre los examinadores. Sin embargo, otros estudios con una muestra más amplia de maloclusiones y un mayor número de examinadores se recomienda para alcanzar resultados más concluyentes.

PALABRAS CLAVE: sistema de clasificación de maloclusión, clasificación de Angle, clasificación de Katz.

\section{REFERENCES}

Ackerman, J. L. \& Proffit, W. R. The characteristics of malocclusion: a modern approach to classification and diagnosis. Am. J. Orthod., 56(5):443-54, 1969.

Andrews, L. F. The six keys to normal occlusion. Am. J. Orthod., 62(3):296-309, 1972.

Angle, E. H. Classification of malocclusion. Dent. Cosmos, 41(3):248-64, 1899.

Asbell, M. B. A brief history of orthodontics. Am. J. Orthod. Dentofacial Orthop., 98(3):206-13, 1990.

Baume, L. J. \& Maréchaux, S. C. Uniform methods for the epidemiologic assessment of malocclusion. Am. J. Orthod., 66(2):121-9, 1974.

Björk, A.; Krebs, A. A. \& Solow, B. A method for epidemiological registration of malocclusion. Acta Odontol. Scand., 22:27-41, 1964.

Brightman, B. B.; Hans, M. G.; Wolf, G. R. \& Bernard, $\mathrm{H}$. Recognition of malocclusion: An education outcomes assessment. Am. J. Orthod. Dentofacial Orthop., 116(4):444-51, 1999.
Cryer, M. H. Typical and atypical occlusion of teeth in relation to the correction of irregularities. Dent. Cosmos., 46(9):713-33, 1904.

Dewey, M. Classification of malocclusion. Int. J. Orthod., 1(2):133-47, 1915.

Du, S. Q.; Rinchuse, D. J.; Zullo, T. G. \& Rinchuse, D. $J$. Reliability of three methods of occlusion classification. Am. J. Orthod. Dentofacial Orthop., 133(4):463-70, 1998.

Draker, H. L. \& Albany, N. Y. Handicapping labio-lingual deviations: a proposed index for public health purpose. Am. J. Orthod., 46(4):295-305, 1960.

Ferreira, A. B. H. New dictionary of Portuguese language. Rio de Janeiro, Ed. Nova Fronteira, 1986.

Gravely, J. F. \& Johnson, D. B. Angle's classification of malocclusion: an assessment of reliability. $\mathrm{Br}$. J. Orthod., 1(3):79-86, 1973.

Grewe, J. M. \& Hagan, D. V. Malocclusion indices: a comparative evaluation. Am. J. Orthod., 61(3):28694, 1972. 
Hellman, M. An interpretation of Angle's classification of malocclusion of the teeth supported by evidence from comparative anatomy and evolution. Dent. Cosmos, 62(4):476-95, 1920.

Hellman, M. Diagnosis in orthodontia and the method of technique I use in practice. Angle Orthod.,; 13(12):3-14, 1943.

Hennet, P. R.; Harvey, C. E. \& Emily, P. P. The Angle classification system of malocclusion: is it appropriate for use in veterinary dentistry? J. Vet. Dent., 9(3):10-2, 1992.

Hermanson, P. C. \& Grewe, J. M. Examiner variability of several malocclusion indices. Angle Orthod., 40(3):219-25, 1970.

Katz, M. I.; Sinkford, J. C. \& Sanders, S. F. The 100year dilemma: what is a normal occlusion and how is malocclusion classifies? Quintessence Int., 21(5):407-14, 1990.

Katz, M. I. Angle classification revisited 2: A modified Angle classification. Am. J. Orthod. Dentofacial Orthop., 103(3):277-84, 1992a.

Katz, M. I. Angle classification revisited 1: Is current use reliable? Am. J. Orthod. Dentofacial Orthop., 102(2):172-9, 1992b.

Lischer, B. E. Principles and methods of orthodontics. Philadelphia, Lea and Febiger, 1912. pp.67-70.

Luke, L. S.; Atchinson, K. A. \& White, S. C. Consistency of patient classification in orthodontic diagnosis and treatment planning. Angle Orthod., 68(6):513-20, 1998.

Miguel-Neto, A. B. \& Mucha, J. N. Malocclusion Classification - A Newly Proposal System for Malocclusion Classification. Ortodontia Gaúcha, 4(1):41-58, 2000.

Moyers, R. E. Orthodontics. 4th ed. Rio de Janeiro, Ed. Guanabara Koogan, 1991. pp.156-66.

Proffit, W. R. \& Ackerman, J. L. Rating the characteristics of malocclusion: A systematic approach for planning treatment. Am. J. Orthod., 64(3):259-69, 1973.

Rinchuse, D. J. \& Rinchuse, D. J. Ambiguities of Angle's classification. Angle Orthod., 112(4):295-8, 1989.
Simon, P. W. The simplified gnathostatic method. Int. J. Orthod., 18(2):1081-7, 1932.

Stoller, A. E. The normal position of the maxillary first permanent molar. Am. J. Orthod., 40(4):259-71, 1954.

Strang, R. H. W. A discussion of the Angle classification and its important bearing on treatment. Angle Orthod., 8(2):182-208, 1938.

Summers, C. J. The occlusal index: A system for identifying and scoring occlusal disorders. Am. J. Orthod., 59(3):553-67, 1971.

Van Loon, J. A. W. A new method for indicating normal and abnormal relations of the teeth to the facial lines. Dent. Cosmos, 57(3):973-83, 1915.

Williams, A. C. \& Stephens, C. D. A modification to the incisor classification of malocclusion. Br. J. Orthod., 19(2):127-30, 1992.

Correspondence to:

Clarice Nishio

Department of Orthodontics, Faculty of Dentistry

Fluminense Federal University

Niterói, Rio de Janeiro, RJ.

BRAZIL

Email: nishiocla@gmail.com

Received: 05-11-2009

Accepted: 12-02-2010 
